Pathophysiology of Haemostasis and Thrombosis
Pathophysiol Haemost Thromb 2003;33:68-74

DOI: $10.1159 / 000073849$
Received: January 9, 2003

Accepted after revision: March 24, 2003

\title{
Effects of the Oral Direct Thrombin Inhibitor Ximelagatran on P-Selectin Expression and Thrombin Generation in Atrial Fibrillation
}

\author{
Michael Wolzt $^{a}$ Stig L. Boström ${ }^{b}$ Mia Svensson ${ }^{b}$ Karin Wåhlander ${ }^{b, c}$ \\ Margaretha Grind ${ }^{d}$ Troy C. Sarich ${ }^{\mathrm{e}}$ \\ aDepartment of Clinical Pharmacology, University of Vienna, Vienna, Austria; ${ }^{b}$ AstraZeneca R\&D, Mölndal, \\ 'Department of Clinical Chemistry and Transfusion Medicine, Sahlgrenska University Hospital, Göteborg, Sweden;

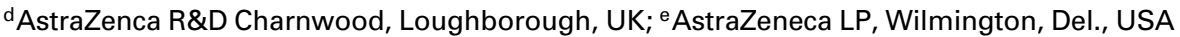

\section{Key Words}

Ximelagatran · Melagatran · P-selectin · Endogenous thrombin potential $\cdot$ Atrial fibrillation

\begin{abstract}
This study investigated the pharmacodynamic effects of the oral direct thrombin inhibitor ximelagatran on platelet activation and thrombin generation in patients with nonvalvular atrial fibrillation. Using an open, groupmatched study design, the effects of ximelagatran (36 mg twice daily for 5 days) were studied in 12 patients with permanent nonvalvular atrial fibrillation and in 12 healthy controls. After ximelagatran for 5 days, elevated platelet $\mathrm{P}$-selectin expression in atrial fibrillation patients was lowered to that during coumarin treatment or in controls but had no effect in control subjects. Using the endogenous thrombin potential as a marker, ximelagatran decreased and delayed thrombin generation in both groups. In conclusion, direct thrombin inhibition with ximelagatran reduced elevated platelet P-selectin expression and inhibited thrombin generation.
\end{abstract}

\section{Introduction}

Atrial fibrillation is the most frequent sustained arrhythmia and is associated with thromboembolic events $[1,2]$. Current guidelines recommend antithrombotic therapy for primary prevention of thromboembolic events in patients with atrial fibrillation at risk for complications [3]. A hypercoagulable state can be detected in patients with permanent atrial fibrillation, even with currently available oral anticoagulant therapy, as shown by increased expression of the platelet membrane adhesion receptor P-selectin $[4,5]$ and elevated levels of soluble Pselectin, plasma von Willebrand factor, and fibrinogen [6].

Thrombin plays a major role in thrombus formation through its ability to catalyze fibrin formation and rapidly activate platelets [7-9] and is, therefore, a key target for anticoagulation treatment. The primary action of thrombin inhibitors is to block thrombin activity directly, without the requirement of cofactors such as antithrombin [10]. Potent thrombin inhibitors have also been shown to decrease thrombin generation via inhibition of thrombin's positive feedback activation of other coagulation

\begin{tabular}{ll}
\hline KARGER & @ 2003 S. Karger AG, Basel \\
1424-8832/03/0332-0068\$19.50/0 \\
$\begin{array}{l}\text { Fax +4161306 1234 } \\
\begin{array}{l}\text { E-Mail karger@karger.ch } \\
\text { www.karger.com }\end{array}\end{array}$ & $\begin{array}{l}\text { Accessible online at: } \\
\text { www.karger.com/pht }\end{array}$
\end{tabular}

Troy C. Sarich, $\mathrm{PhD}$

Experimental Medicine, AstraZeneca LP

PO Box 15347, C4C-123

Wilmington, DE 19850 (USA)

Tel. +1 302885 8979, Fax +1 302886 3386, E-Mail troy.sarich@astrazeneca.com 


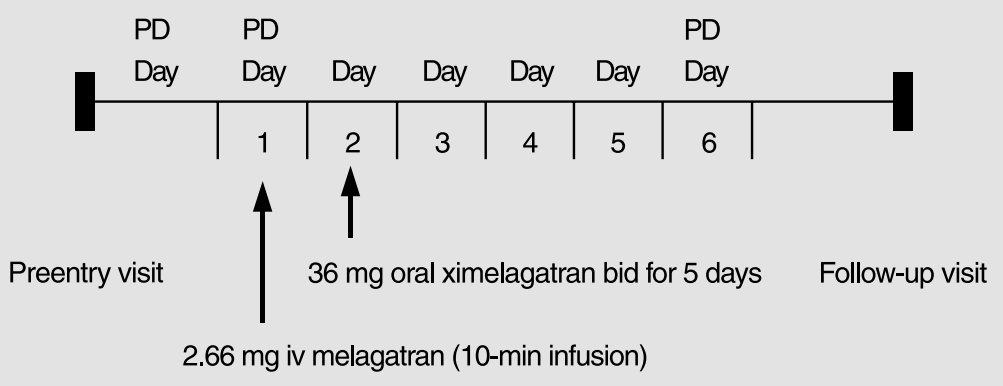

Fig. 1. Study design. $P D=$ Blood samples collected for pharmacodynamic evaluation.

factors as suggested by reduced formation of coagulation activation markers or thrombin generation assays [1114]. As formation of the highly reactive thrombin is not assessable directly in humans in vivo, clinical studies rely on the measurement of activation markers formed during clotting and ex vivo tests. Among the latter, the endogenous thrombin potential (ETP) assay has been established as a unique method to assess hypercoagulability and to measure anticoagulant treatment in plasma $[15,16]$.

Ximelagatran is an oral direct thrombin inhibitor that is rapidly absorbed and bioconverted to its active form melagatran, with low interindividual variability in plasma melagatran concentrations $[13,17]$. The objective of the current study was to determine whether platelet activation (expression of platelet $\mathrm{P}$-selectin) and thrombin generation, as assessed by determination of the ETP and time to thrombin peak, are altered in patients with permanent nonvalvular atrial fibrillation and if these changes can be normalized by direct thrombin inhibition with ximelagatran.

\section{Methods}

\section{Subjects}

A total of 12 patients with permanent nonvalvular atrial fibrillation at least 19 years of age and weighing $50-120 \mathrm{~kg}$ with a low or moderate risk for stroke [3] receiving oral anticoagulant treatment and 12 healthy control subjects, matched for age and sex, were included in the study. This study was approved by the Ethics Committee of the Vienna University and the Allgemeines Krankenhaus Wien and was performed in compliance with the Declaration of Helsinki, including current revisions, and the Good Clinical Practice guidelines. Written informed consent was obtained from all subjects prior to enrollment.

Ximelagatran on P-Selectin and ETP in Atrial Fibrillation

\section{Study Design}

The study followed an open, nonrandomized, group-matched study design and consisted of a 6-day treatment period (fig. 1). The preexisting oral anticoagulant treatment with the vitamin K antagonist coumarin in atrial fibrillation patients was discontinued at study entry, at an international normalized ratio (INR) of between 2.1 and 3.1 (median 2.4). Treatment with melagatran was started at an INR of $\leq 2.0$, which was between 3 and 9 days (median 7 days) after study entry. All subjects received a 10-min intravenous infusion of $2.66 \mathrm{mg}$ melagatran on the first study day (day 1), followed by $36 \mathrm{mg}$ oral ximelagatran twice daily at 12-hour dosing intervals on the 5 subsequent study days. As the half-life of melagatran is approximately $4-5 \mathrm{~h}$ in atrial fibrillation patients after oral dosing with ximelagatran [18], a 5-day treatment period of repeated dosing was considered adequate to reach steady state.

\section{Blood Sampling}

The INR was measured from citrated venous plasma at study entry and on day 1 employing routine laboratory methods. Citrated venous blood samples $(0.5 \mathrm{ml} \mathrm{3.8 \%}$ sodium citrate) for the determination of platelet P-selectin expression, ETP and activated partial thromboplastin time (APTT) were taken at study entry, on day 1 before initiation of melagatran, and $2 \mathrm{~h}$ after the morning dose of ximelagatran on day 6 .

\section{Analyses}

Plasma Melagatran. Plasma concentrations of melagatran were measured using liquid chromatography-mass spectrometry [19]. The limit of quantification was $0.010 \mu \mathrm{mol} / \mathrm{l}$.

Platelet P-Selectin Expression. Platelet P-selectin (CD62P) analysis was performed after incubation of citrated blood with fluorescein isothiocyanate-labeled anti-P-selectin antibody (Immunotech, Marseille, France) using flow cytometry (fluorescence-activated cell sorter scan; Becton Dickinson, San Jose, Calif., USA) [20]. An isotopespecific monoclonal antibody was used to set a threshold for positive platelets (IgG1; Immunotech), and the fluorescein-positive number expressed as percentage of total platelets analyzed.

Endogenous Thrombin Potential. ETP was determined as previously described [15] and as follows: $100 \mu \mathrm{l}$ prewarmed plateletpoor plasma was combined with $15 \mu \mathrm{l}$ thrombin chromogenic substrate H- $\beta$-Ala-Gly-Arg-pNA ( $5 \mathrm{mmol} / \mathrm{l}), 12.5 \mu \mathrm{l}$ fibrin polymerization inhibitor H-Gly-Pro-Arg-Pro-OH-AcOH (36 mg/ml), and $100 \mu \mathrm{l}$ 
Table 1. Platelet P-selectin expression (\% of total platelets) in patients with permanent nonvalvular atrial fibrillation and controls at study entry, at baseline with an INR $\leq 2.0$ before dosing on day 1 , and $2 \mathrm{~h}$ after $36 \mathrm{mg}$ oral ximelagatran on day 6

\begin{tabular}{lcl}
\hline & Patients & Controls \\
\hline P-selectin expression & & \\
Study entry & $9.8(7.0 ; 12.6)$ & $8.2(5.8 ; 10.7)$ \\
Baseline (day 1) & $10.9(9.0 ; 12.9)^{*}$ & $7.5(5.3 ; 9.7)$ \\
Ximelagatran (day 6) & $9.2(6.2 ; 12.1)$ & $7.0(5.2 ; 8.8)$ \\
\hline
\end{tabular}
trols.

Data are presented as mean $(95 \% \mathrm{CI}), \mathrm{n}=12 .^{*} \mathrm{p}<0.05$ vs. con-

Thromborel S (diluted 1:20), and the change in absorbance was recorded at $405 \mathrm{~nm}$ over a period of $20 \mathrm{~min}$ (Spectra MaxPlus microtiterplate reader; Molecular Devices, Sunnyvale, Calif., USA). Thrombin activity was calculated from the optical density trace with the computer program Pure Thrombin (AstraZeneca, Mölndal, Sweden) using the concentration and kinetic constants of the thrombin chromogenic substrate H- $\beta$-Ala-Gly-Arg-pNA $\left(\mathrm{K}_{\mathrm{m}}=1.95 \mathrm{mmol} / \mathrm{l}\right.$, $\mathrm{K}_{\text {cat }}=1.91 / \mathrm{s}$ ) [12]. The total amidolytic activity over time was then corrected for the presence of thrombin- $\alpha_{2}$ macroglobulin complexes. The algorithm calculates the time constant, $\kappa$, from the conversion of thrombin into its complex with $\alpha_{2}$-macroglobulin for each individual sample. The ratio of $\mathrm{k}_{\text {cat } 1} / \mathrm{k}_{\text {cat } 2}$ is also calculated for each individual sample, where $\mathrm{k}_{\text {cat } 1}=$ the time constant for the conversion of the substrate into product by thrombin, $\mathrm{k}_{\mathrm{cat} 2}=$ the time constant for the conversion of the substrate into product by the $\alpha_{2}$-macroglobulin-thrombin complex. As thrombin generation continues, all thrombin is finally converted into the complex between $\alpha_{2}$-macroglobulin and thrombin, and as the time constant $\mathrm{k}_{\text {cat } 2}$ is known, the activity of this complex can be calculated and subtracted.

Activated Partial Thromboplastin Time. APTT measurements were performed using Thrombolytic Assessment System-APTT assay cards with an automated Thrombolytic Assessment System card reader (TAS ${ }^{\mathrm{TM}}$; Pharmanetics, Morrisville, N.C., USA) [13]. The Thrombolytic Assessment System-APTT technique results in APTT values that are higher than those that would be obtained using conventional APTT methods.

\section{Safety Evaluations}

All subjects were given a complete health examination (including physical examination and laboratory screening) at study entry and at follow-up 2-5 days after the last study day, and all adverse events were recorded.

\section{Statistical Analysis}

Descriptive statistics were calculated for all pharmacodynamic variables. The matched pairs were used for comparisons of the levels of P-selectin and analysis of parameters of the ETP and time to thrombin peak between the two groups. For P-selectin and ETP, changes within groups between measurement occasions and changes between groups on each measurement occasion were determined and given as means with $95 \%$ confidence intervals ( $95 \%$ CIs). Group dif-
Table 2. ETP and time to thrombin peak in patients with permanent nonvalvular atrial fibrillation and controls at study entry, at baseline with an INR $<2.0$ before dosing on day 1 , and $2 \mathrm{~h}$ after $36 \mathrm{mg}$ oral ximelagatran on day 6

\begin{tabular}{lcc}
\hline & Patients & Controls \\
\hline ETP, nmol/l·min & & \\
Study entry & $921(653 ; 1,188)^{*}$ & $1,601(1,085 ; 2,117)$ \\
Baseline (day 1) & $1,271(948 ; 1,594)$ & $1,336(1,022 ; 1,651)$ \\
Ximelagatran (day 6) & $777(603 ; 950)^{++}$ & $846(644 ; 1,047)^{+,++}$ \\
\hline Time to thrombin peak, $\min$ & \\
Study entry & $3.48(2.64 ; 4.33)^{*}$ & $2.06(1.75 ; 2.38)$ \\
Baseline (day 1) & $2.42(1.93 ; 2.92)^{*++}$ & $1.86(1.62 ; 2.09)$ \\
Ximelagatran (day 6) & $4.63(2.99 ; 6.28)^{++}$ & $3.06(2.30 ; 3.81)^{+,++}$ \\
& & \\
\hline
\end{tabular}

Data are presented as mean $(95 \% \mathrm{CI}), \mathrm{n}=12 .{ }^{*} \mathrm{p}<0.05$ vs. controls; ${ }^{+} \mathrm{p}<0.05$ vs. study entry; ${ }^{++} \mathrm{p}<0.05$ vs. day 1 .

ferences/ratios were considered statistically significant at 2-tailed level of $0.05(\mathrm{p}<0.05)$ when the $95 \%$ CIs of the differences/ratios did not cross $0.0 / 1.0$ (excluding $0.0 / 1.0$ ). No corrections were to be made for multiple comparisons performed in this study. A linear model was fitted for patients and controls on day 6 to investigate the relationship between the APTT ratio (expressing APTT as a ratio of predose values) as the dependent variable and with plasma concentrations of melagatran, health status (patient no/yes), and the interaction between plasma concentration of melagatran and health status (patient no/yes) as explanatory variables. Previous studies have shown that a linear relationship with APTT ratio is produced when a square-root transformation of plasma concentrations of melagatran is used rather than a curvilinear relationship with absolute melagatran concentrations.

\section{Results}

\section{Subjects}

A total of 12 patients with permanent nonvalvular atrial fibrillation and 12 healthy control subjects were included in the study. All subjects were Caucasians; 7 pairs were men and 5 pairs were women. The median (range) age of the atrial fibrillation patients was 65 years (37-77) and of the matched controls 63 years (32-77). The median (range) body mass index values were $29.8 \mathrm{~kg} /$ $\mathrm{m}^{2}(24.3-37.6)$ and $28.0 \mathrm{~kg} / \mathrm{m}^{2}(20.3-38.1)$ for patients and controls, respectively. After discontinuation of coumarin treatment in patients with atrial fibrillation at study entry, the INR decreased to between 0.9 and 2.0 (median 1.5) before melagatran dosing. 
Table 3. APTT and plasma melagatran concentrations in patients with permanent nonvalvular atrial fibrillation and controls after 5 days of oral ximelagatran treatment (day 6) at predose, and after $36 \mathrm{mg}$ oral ximelagatran

\begin{tabular}{clllll}
\hline & \multicolumn{2}{l}{ APTT, $\mathrm{s}$} & & \multicolumn{2}{l}{ Plasma melagatran, $\mu \mathrm{mol} / \mathrm{l}$} \\
\cline { 2 - 3 } \cline { 5 - 6 } & patients & controls & & patients & controls \\
\hline Predose & $54 \pm 12$ & $45 \pm 8$ & & $0.132 \pm 0.065$ & $0.103 \pm 0.036$ \\
$2 \mathrm{~h}$ & $66 \pm 16$ & $67 \pm 12$ & & $0.348 \pm 0.193$ & $0.336 \pm 0.159$ \\
$3 \mathrm{~h}$ & $79 \pm 29$ & $70 \pm 6$ & & $0.412 \pm 0.168$ & $0.374 \pm 0.112$ \\
$6 \mathrm{~h}$ & $66 \pm 11$ & $60 \pm 8$ & & $0.300 \pm 0.105$ & $0.257 \pm 0.080$ \\
$8 \mathrm{~h}$ & $59 \pm 10$ & $49 \pm 8$ & & $0.215 \pm 0.090$ & $0.174 \pm 0.059$ \\
$12 \mathrm{~h}$ & $46 \pm 9$ & $43 \pm 9$ & & $0.113 \pm 0.057$ & $0.086 \pm 0.032$ \\
\hline
\end{tabular}

Data are presented as mean $\pm \mathrm{SD}, \mathrm{n}=12$. The APTT was measured using a bedside Thrombolytic Assessment System-APTT, which tends to overestimate the APTT prolongation as compared with conventional APTT assays.

\section{Platelet P-Selectin Expression}

Platelet P-selectin data are summarized in table 1. In atrial fibrillation patients, P-selectin expression on platelets was slightly higher at baseline (day 1) compared with study entry and was lower during ximelagatran treatment (day 6). However, these within-group changes were small and did not reach statistical significance. The control group had relatively constant P-selectin levels in the absence and presence of melagatran. Platelet P-selectin expression on day 1 was significantly higher (approximately $45 \%$ ) in atrial fibrillation patients when the international normalized ratio was $\leq 2.0$ than in control subjects (mean difference $3.41,95 \% \mathrm{CI}$ : $0.59 ; 6.24)$. On day 6 , this difference was no longer detectable (mean difference 2.14 , 95\% CI: -0.47 ; 4.75).

\section{Endogenous Thrombin Potential}

ETP results are shown in table 2. Within atrial fibrillation patients, ETP was slightly higher $(p>0.05)$ and time to thrombin peak shorter $(\mathrm{p}<0.05)$ at baseline on day 1 with an INR of $\leq 2.0$ compared with values at study entry. In control subjects, ETP and time to thrombin peak were comparable at study entry and day 1 . Ximelagatran treatment (day 6) significantly decreased ETP versus day 1 in both patients (mean difference $-495 ; 95 . \% \mathrm{CI}$ : -747 ; $-242)$ and controls (-491, 95\% CI: $-739 ;-243)$. Time to thrombin peak was prolonged between day 1 and day 6 in patients (mean difference $2.21 ; 95 \%$ CI: $0.76 ; 3.67$ ) and controls $(1.2 ; 95 \% \mathrm{CI}: 0.43 ; 1.97)$. Between-group differences were detectable at study entry, where patients had a

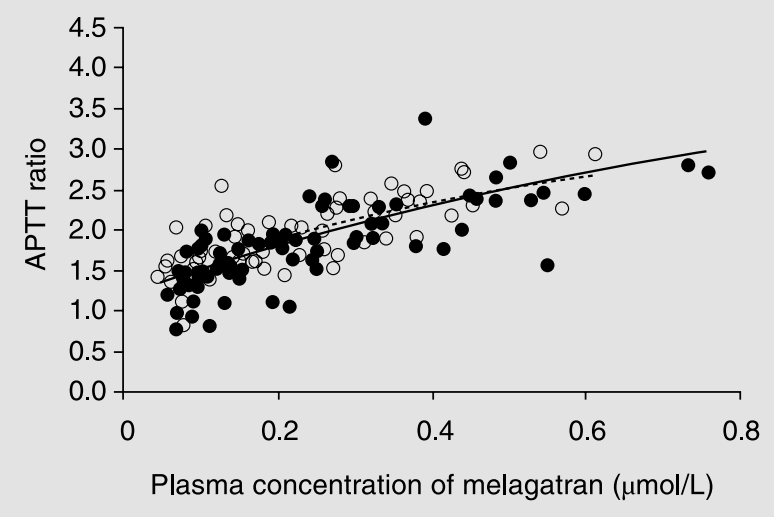

Fig. 2. Individual relationship between APTT ratio and plasma melagatran concentrations after $36 \mathrm{mg}$ oral ximelagatran in patients with permanent nonvalvular atrial fibrillation $(O)$ and controls $(O)$ on day 6. APTT is expressed as a ratio of predose values on day 1 . The predicted and observed APTT ratios versus melagatran plasma concentrations are shown $\left(\mathrm{R}^{2}=0.46\right)$. The slope of the relationship was 2.7 APTT ratio/ $(\mu \mathrm{mol} / 1 \text { melagatran })^{0.5}$ in patients $(95 \% \mathrm{CI}: 1.1$; $4.3)$ and 2.4 APTT ratio/ $(\mu \mathrm{mol} / 1 \text { melagatran })^{0.5}$ in controls $(95 \% \mathrm{CI}$ : $1.7 ; 3.1)$, respectively, which was similar between groups.

lower ETP (mean difference -680, 95\% CI: $-1,235 ;-125$ ) and longer time to thrombin peak $(1.42,95 \%$ CI 0.46 ; 2.38) than the control group. Before dosing with melagatran on day 1, ETP was comparable in patients and controls, but time to thrombin peak was still prolonged in atrial fibrillation patients $(0.57,95 \% \mathrm{CI}: 0.04 ; 1.1) \mathrm{com}-$ pared with controls. ETP parameters were comparable between groups during ximelagatran treatment on day 6 .

\section{Activated Partial Thromboplastin Time}

On day 1 , after discontinuation of oral anticoagulant treatment with coumarin and at an INR of $\leq 2.0$, the mean (range) APTT was comparable between patients with permanent atrial fibrillation $(33.8 \mathrm{~s} ; 26.4-52.1 \mathrm{~s})$ and controls (29.4 s; 23.7-34.7 s). Ximelagatran on day 6 increased plasma melagatran concentrations and prolonged the APTT in patients and controls, with a similar response to ximelagatran in both groups (table 3 , fig. 2).

\section{Safety}

Patients with atrial fibrillation reported more adverse events during the study than controls: 3 minor bleeding events, blood in sputum, gingival bleeding and a mild hematoma were reported by 3 patients during study treat- 
ment, and 1 case of mild epistaxis was reported during the follow-up period. There were no bleeding events in control subjects.

\section{Discussion}

In this study, oral administration of ximelagatran at steady state reduced platelet expression of P-selectin to that during coumarin treatment or that observed in controls and decreased the ETP and prolonged time to thrombin peak in patients with permanent nonvalvular atrial fibrillation. Ximelagatran significantly lowered platelet Pselectin expression in patients to that of healthy matched controls, whereas parameters assessed from plasma thrombin generation were altered with both groups to a similar degree. These effects were observed in the presence of similar prolongations of the APTT in patients and controls, confirming a consistent anticoagulant effect of ximelagatran between these two groups. The small number of individuals in this study makes it difficult to interpret the significance of the 3 minor bleeds observed in the patient group versus none in the control group during treatment with ximelagatran.

The elevation of platelet $\mathrm{P}$-selectin expression in atrial fibrillation patients (at INR $\leq 2.0$ ) suggests a higher degree of systemic platelet activation than in controls and is consistent with other reports [4, 5, 21]. Interestingly, platelet activation and atrial fibrillation are not related to increases in heart rate by exercise [22] or by ventricular pacing or increased right atrial pressure [5] but are associated with the risk for embolism [23, 24]. This finding is also consistent with studies on venous plasma concentrations of soluble P-selectin, which are consistently increased in permanent atrial fibrillation $[4,6,22,25,26]$ irrespective of the site of blood sampling [27]. Enhanced plasma concentrations of soluble P-selectin were reported in a recent study after 6 weeks of warfarin treatment in patients with atrial fibrillation, despite reduced prothrombin fragment $1+2$ and $\beta$-thromboglobulin concentrations [26]. Since soluble P-selectin may not only indicate platelet activation but is also related to platelet destruction by the reticuloendothelial system, the relevance of this finding is unclear and must be interpreted cautiously. The present study is the first describing the actions of direct thrombin inhibitors on platelet P-selectin expression in patients with atrial fibrillation. Our results showing that ximelagatran can reduce elevated platelet Pselectin expression in atrial fibrillation patients to that of controls is in line with the decrease in soluble P-selectin by unfractionated heparin in healthy men reported previously [28]. Although the mechanism of platelet activation in atrial fibrillation appears to be related to thrombin formation, the exact regulation of the platelet P-selectin membrane expression is complex [29] and, to our knowledge, has not been investigated in detail. The involvement of thrombin and the importance of anticoagulation in atrial fibrillation were recently demonstrated in a study in which warfarin therapy was found to be effective at reducing plasma indices of thrombogenesis and platelet activation in atrial fibrillation patients, whereas aspirin-clopidogrel combination therapy failed to reduce plasma indices of thrombogenesis and platelet activation [26]. Understanding and comparing the degree of inhibition of thrombin generation and platelet activation by antithrombotic drugs may help guide the selection of effective doses as regards P-selectin expression on platelets.

To date, the in vitro plasma potency to generate thrombin as measured by the ETP has not been used to determine coagulability in routine laboratories. In several studies, thromboembolic risk, associated with oral contraceptive therapies [30], coronary artery disease [31], hyperhomocysteinemia [32] and factor V Leiden in women [33], has been assessed. The observation in the present study of decreased thrombin generation and delayed peak thrombin burst during oral anticoagulation in atrial fibrillation patients with vitamin $\mathrm{K}$ antagonists is consistent with previous data [31]. The discontinuation of oral anticoagulation in atrial fibrillation patients resulted in an ETP that approximated those of controls, clearly demonstrating its dependency on concomitant anticoagulant therapy. Thus, even if hypercoagulability is present in permanent atrial fibrillation, there is little if any impact on plasma thrombin generation parameters, contrary to P-selectin expression and other parameters reflecting thrombogenicity.

It has been demonstrated in vitro and ex vivo that the direct thrombin inhibitor hirudin delayed thrombin generation $[14,34,35]$ and in one study also decreased ETP [35], whereas the low-molecular-weight heparin dalteparin reduced ETP but had only a negligible effect on the time to thrombin peak [35]. In contrast, melagatran both delays time to the thrombin peak and inhibits ETP efficiently ex vivo. This was demonstrated in a clinical setting in healthy subjects, where the melagatran-induced reduction in the area under the thrombin generation curve was dose-dependent [35]. After a single dose of 30 or $60 \mathrm{mg}$ ximelagatran, ex vivo ETP decreased to approximately 71 and $52 \%$ of baseline values at a mean melagatran plasma concentration of 0.25 and $0.46 \mu \mathrm{mol} / 1$, respectively. These experiments are consistent with the decrease of 
ETP to approximately $63 \%$ from predose for control subjects in our study and demonstrate that parameters derived from plasma thrombin generation are suited to provide additional information to assays of thrombin inhibition, as they enable estimation of anticoagulant effects of vitamin $\mathrm{K}$ antagonists or direct thrombin inhibitors on thrombin generation. During ximelagatran treatment, both ETP and time to thrombin peak were comparably reduced in atrial fibrillation patients and healthy controls, and thrombin generation was inhibited accordingly.

In conclusion, permanent nonvalvular atrial fibrillation has been shown to increase platelet membrane $\mathrm{P}$ - selectin expression in patients with an INR $\leq 2.0$ versus controls. Direct thrombin inhibition with ximelagatran lowered elevated P-selectin expression and inhibited parameters of thrombin formation of the plasma thrombin generation curve.

\section{Acknowledgments}

The authors gratefully acknowledge the contributions of Carola Fuchs, RN, Maria Wollbratt, MSc, and Ulf Eriksson, PhD, to this study. The study was funded by AstraZeneca.

\section{References}

1 Wolf PA: Prevention of stroke. Lancet 1998; 352(suppl 3):SIII-15-SIII-18.

2 Hart RG, Sherman DG, Easton JD, Cairns JA: Prevention of stroke in patients with nonvalvular atrial fibrillation. Neurology 1998;51:674681.

3 Fuster V, Ryden LE, Asinger RW, Cannom DS, Crijns HJ, Frye RL, Halperin JL, Kay GN, Klein WW, Levy S, McNamara RL, Prystowsky EN, Wann LS, Wyse DG: ACC/AHA/ESC guidelines for the management of patients with atrial fibrillation. A report of the American College of Cardiology/American Heart Association Task Force on Practice Guidelines and the European Society of Cardiology Committee for Practice Guidelines and Policy Conferences (Committee to develop guidelines for the management of patients with atrial fibrillation) developed in collaboration with the North American Society of Pacing and Electrophysiology. Eur Heart J 2001;22:1852-1923.

4 Blann AD, Li-Saw-Hee F, Lip GY, Minamino T, Kitakaze M, Sanada S, Asanuma H, Kurotobi T, Koretsune Y, Fukunami M, Kuzuya T, Hoki N, Hori M: Increased membrane and soluble P-selectin in atrial fibrillation. Circulation 1999; 100:e86-e87.

5 Goette A, Ittenson A, Hoffmanns P, Reek S, Hartung W, Klein H, Ansorge S, Geller JC: Increased expression of $\mathrm{P}$-selectin in patients with chronic atrial fibrillation. PACE 2000;23: 1872-1875.

6 Li-Saw-Hee FL, Blann AD, Gurney D, Lip GY Plasma von Willebrand factor, fibrinogen and soluble P-selectin levels in paroxysmal, persistent and permanent atrial fibrillation. Effects of cardioversion and return of left atrial function. Eur Heart J 2001;22:1741-1747.

7 Michelson AD: Platelet activation by thrombin can be directly measured in whole blood through the use of the peptide GPRP and flow cytometry: Methods and clinical applications. Blood Coagul Fibrinolysis 1994;5:121-131.
8 Becker RC, Bovill EG, Seghatchian MJ, Samama MM: Pathobiology of thrombin in acute coronary syndromes. Am Heart J 1998;136: S19-S31.

9 Fenton JW 2nd, Ofosu FA, Brezniak DV, Hassouna HI: Thrombin and antithrombotics. Semin Thromb Haemost 1998;24:87-91.

10 Hauptmann J, Stürzebecher J: Synthetic inhibitors of thrombin and factor Xa: From bench to bedside. Thromb Res 1999;93:203-241.

11 Eichinger S, Wolzt M, Schneider B, NieszpaurLos M, Heinrichs H, Lechner K, Eichler HG, Kyrle PA: Effects of recombinant hirudin (rhirudin, HBW 023) on coagulation and platelet activation in vivo: Comparison with unfractionated heparin and a low-molecular-weight heparin preparation (Fragmin). Arterioscler Thromb Vasc Biol 1995; 15:886-892.

12 Prasa D, Svendsen L, Stürzebecher J: The ability of thrombin inhibitors to reduce the thrombin activity generated in plasma on extrinsic and intrinsic activation. Thromb Haemost 1997;77:498-503.

13 Sarich TC, Wolzt M, Eriksson UG, Mattsson C, Schmidt A, Elg S, Andersson M, Wollbratt M, Fager G, Gustafsson D: Effects of ximelagatran, an oral direct thrombin inhibitor, r-hirudin and enoxaparin on thrombin generation and platelet activation in healthy male subjects. J Am Coll Cardiol 2003;41:557-564.

14 Lindhout T, Blezer R, Hemker HC: The anticoagulant mechanism of action of recombinant hirudin (CGP39393) in plasma. Thromb Haemost 1990;64:464-468.

15 Hemker HC, Wielders S, Kessles H, Beguin S: Continuous registration of thrombin generation in plasma, its use for the determination of the thrombin potential. Thromb Haemost 1993; 70:617-624.

16 Hemker HC, Beguin S: Thrombin generation in plasma: Its assessment via the endogenous thrombin potential. Thromb Haemost 1995; $74: 134-138$.
17 Eriksson UG, Bredberg U, Gislen K, Johansson LC, Frison L, Ahnoff M, Gustafsson D: Pharmacokinetics and pharmacodynamics of ximelagatran, a novel oral direct thrombin inhibitor, in young healthy male subjects. Eur $\mathrm{J}$ Clin Pharmacol 2003;59:35-43.

18 Grind M, Hamrén B, Bååthe $\mathrm{S}$, Wollbratt M, Eriksson UG: Pharmacokinetics of the oral direct thrombin inhibitor ximelagatran in patients with nonvalvular atrial fibrillation receiving long-term treatment: A population analysis by nonlinear mixed effect modeling (abstract). Clin Pharmacol Ther 2002;71:P31.

19 Larsson M, Logren U, Ahnoff M, Lindmark B, Abrahamsson P, Svennberg H, Persson BA: Determination of melagatran, a novel, direct thrombin inhibitor, in human plasma and urine by liquid chromatography-mass spectrometry. J Chromatogr B Biomed Sci Appl 2002;766:47-55.

20 Stohlawetz P, Horvath M, Pernerstorfer T, Nguyen H, Vondrovec B, Robisch A, Eichler HG, Spitzauer S, Jilma B: Effects of nitric oxide on platelet activation during plateletpheresis and in vivo tracking of biotinylated platelets in humans. Transfusion 1999;39:506514.

21 Minamino T, Kitakaze M, Asanuma H, Ueda Y, Koretsune Y, Kuzuya T, Hori M: Plasma adenosine levels and platelet activation in patients with atrial fibrillation. Am J Cardiol 1999;83:194-198.

22 Li-Saw-Hee FL, Blann AD, Edmunds E, Gibbs CR, Lip GY: Effect of acute exercise on the raised plasma fibrinogen, soluble P-selectin and von Willebrand factor levels in chronic atrial fibrillation. Clin Cardiol 2001;24:409_ 414.

23 Minamino T, Kitakaze M, Sanada S, Asanuama H, Kurotobi T, Koretsune Y, Fukunami M, Kuzuya T, Hoki N, Hori M: Increased expression of $\mathrm{P}$-selectin on platelets is a risk factor for silent cerebral infarction in patients with atrial fibrillation: Role of nitric oxide. Circulation 1998;98:1721-1727. 
24 Pongratz C, Brandt-Pohlmann M, Henneke KH, Pohle C, Zink D, Gehling G, Bachmann $\mathrm{K}$ : Platelet activation in embolic and preembolic status of patients with nonrheumatic atrial fibrillation. Chest 1997;111:929-933.

25 Li-Saw-Hee FL, Blann AD, Lip GY: A crosssectional and diurnal study of thrombogenesis among patients with chronic atrial fibrillation. J Am Coll Cardiol 2000;35:1926-1931.

26 Kamath S, Blann AD, Chin BS, Lip GY: A prospective randomized trial of aspirin-clopidogrel combination therapy and dose-adjusted warfarin on indices of thrombogenesis and platelet activation in atrial fibrillation. $\mathbf{J}$ Am Coll Cardiol 2002;40:484-490.

27 Li-Saw-Hee FL, Blann AD, Goldsmith I, Lip GY: Indexes of hypercoagulability measured in peripheral blood reflect levels in intracardiac blood in patients with atrial fibrillation secondary to mitral stenosis. Am J Cardiol 1999;83: 1206-1209.
28 Pernerstorfer T, Eichler HG, Stohlawetz P, Speiser W, Jilma B: Effects of heparin and aspirin on circulating P-selectin. E-selectin and von Willebrand factor levels in healthy men. Atherosclerosis 2001;155:389-393.

29 Barkalow FJ, Barkalow KL, Mayadas TN: Dimerization of P-selectin in platelets and endothelial cells. Blood 2000;96:3070-3077.

30 Tans G, Curvers J, Middeldorp S, Thomassen MC, Meijers JC, Prins MH, Bouma BN, Buller HR, Rosing J: A randomized cross-over study on the effects of levonorgestrel- and desogestrel-containing oral contraceptives on the anticoagulant pathways. Thromb Haemost 2000; $84: 15-21$.

31 Wielders S, Mukherjee M, Michiels J, Rijkers DT, Cambus JP, Knebel RW, Kakkar V, Hemker HC, Beguin S: The routine determination of the endogenous thrombin potential, first results in different forms of hyper- and hypocoagulability. Thromb Haemost 1997;77: 629-636.
32 Bos GM, Rijkers DT, Willems HP, den Heijer M, Beguin S, Gerrits WB, Hemker HC: The elevated risk for venous thrombosis in persons with hyperhomocysteinemia is not reflected by the endogenous thrombin potential. Thromb Haemost 1999;81:467-468.

33 Eichinger S, Weltermann A, Phillipp K, Hafner E, Kaider A, Kittl EM, Brenner B, Mannhalter C, Lechner K, Kyrle PA: Prospective evaluation of hemostatic system activation and thrombin potential in healthy pregnant women with and without factor V Leiden. Thromb Haemost 1999;82:1232-1236.

34 Peyrou V, Lormeau JC, Herault JP, Gaich C, Pfliegger AM, Herbert JM: Contribution of erythrocytes to thrombin generation in whole blood. Thromb Haemost 1999;81:400-406.

35 Boström SL, Sarich TC, Wolzt M: The effects of melagatran, the active form of $\mathrm{H} 376 / 95$, an oral, direct thrombin inhibitor, on thrombin generation (abstract). Blood 2000;96:56a. 